\title{
Magdalena de Cao y la arqueología colonial en el Perú
}

\author{
Jeffrey Quilter ${ }^{a}$
}

\section{Resumen}

Al presentar este ensayo, deseo explorar cómo algunos de nuestros hallazgos en los estudios en Magdalena de Cao Viejo, en el valle de Chicama, se relacionan con la cuestión de examinar identidades en un sitio del Periodo Colonial Temprano. Empezaré por describir el sitio en general y, luego, me enfocaré en lineas clave de evidencia de los problemas y potencialidades de identificar asimilación, acomodación, hibridación y resistencia a través de la arqueología, especialmente, en nuestro programa de estudios desde el año 2004 hasta el presente.

Palabras clave: Magdalena de Cao Viejo, Periodo Colonial Temprano, arqueología histórica

\section{Abstract}

\section{MAGDALENA DE CAO AND COLONIAL ARCHAEOLOGY IN PERU}

With this essay, I want to explore how some of our findings during the fieldwork at Magdalena de Cao Viejo, Chicama Valley, are related with the examination of identities in an Early Colonial Period site. First, I describe the site and then focus on in key lines of evidence about problems and potentialities to identify assimilation, accommodation, hybridization and resistance through archaeological methods since the beginning of the project to the present.

Keywords: Magdalena de Cao Viejo, Early Colonial Period, Historical Archaeology

a Programa de Arqueología/ Museo de Arqueología y Etnología Peabody, Harvard University Correo electrónico: quilter@fas.harvard.edu 


\section{Introducción}

Aunque la tradición local menciona que Magdalena de Cao fue fundada en 1538, es más probable que fuera establecida en 1566 como una de cuatro reducciones: Santa María Magdalena de Cao, Santiago de Cao, San Salvador de Paiján, y San Pedro y San Pablo de Chocope (Castañeda 2006, 2007). Esta primera Magdalena se ubicaba en la desembocadura de uno de los ramales del río Chicama. En 1578, un fuerte fenómeno de El Niño trajo fuertes inundaciones que destruyeron la primera Magdalena de Cao y otros poblados cercanos al río. Testimonios registrados después del evento incluyen una declaración que narra cómo los «magdaleneros» huyeron a «un pueblo ubicado junto al océano a una altura donde se quedaron y aún hoy habitan» (Autor año ).

Fundada por miembros de la orden religiosa dominicana, el complejo de la iglesia fue construido en el extremo norte de la plaza de la Huaca Moche de Cao Viejo (Fig. 1). Los edificios en el complejo consistían de una iglesia en su centro, orientada norte-sur, con un atrio abierto; el cementerio del pueblo al oeste; y el conjunto de edificios que incluyen residencias, oficinas, área de cocina y otras habitaciones al este, la mayoría sobre una plataforma prehistórica en la esquina noreste de la plaza (Fig. 2).

Al norte del complejo de la iglesia y a un nivel inferior, el pueblo estaba organizado en un patrón de cuadrícula con calles norte-sur, comúnmente de 2,5 metros de ancho, que se alinea en el mismo eje que la huaca y la plaza, a unos 13 grados este-norte, con calles que interceptan y van de este a oeste. Una larga plaza (aproximadamente, de 75 metros por 75 metros) fue ubicada encuadrada con el atrio y con sectores de la nave del complejo de la iglesia.

Los bloques de residencias alrededor de la plaza consisten en conjuntos definidos por muros de quincha. Aunque puede haber existido un rango de tamaño, estos conjuntos parecen haber sido rectangulares, y medido casi 15 metros de ancho y 20 a 25 metros de largo. Estos se dividían internamente en un gran patio, donde se guardaban los animales y se realizaba el trabajo al aire libre, y dos o tres habitaciones pequeñas para el descanso y actividades bajo techo.

A la fecha, dos conjuntos residenciales han sido excavados extensivamente y un tercero ha sido parcialmente excavado (Fig. 3). Todo demuestra que la misma secuencia de ocupación se inicia con un asentamiento que se ubicó directamente sobre restos de ocupación prehistórica. A través del tiempo, se sucedieron modificaciones a las estructuras incluidas la construcción de fogones; la acumulación de cenizas y otros lentes de tierra sobre los pisos; y, sobre todo, pequeñas reorganizaciones de habitaciones a través de la utilización de adobe, algunos de los cuales fueron reinados de la era prehistórica, probablemente de las estructuras moche. El área doméstica del sitio cambió dramáticamente, como lo evidencian gruesos lentes de cenizas (de más de 10 centímetros) que luego fueron cubiertos por densos depósitos (de aproximadamente 30 centímetros) de estiércol de animales y de paja. La naturaleza residencial del sitio parece haber cambiado de una comunidad de personas a un lugar de relativamente poca gente, pero con un gran número de ovejas y cabras.

El complejo de la iglesia experimentó un cambio incluso más dramático que el pueblo. Encontramos grandes secciones de las paredes de la nave de la iglesia que colapsaron hacia el este, en el área de la cocina del conjunto residencial. En lo que respecta al patrón de caída del muro, este pudo haberse dado tras un significativo evento sísmico. Si el incidente causó el abandono de la iglesia o si algún tiempo pasó antes de que la comunidad religiosa se fuera, aún no queda claro.

El colapso del muro atrapó muchos objetos y, si es que hubo algún intento de recuperar los de importancia, no se invirtió el esfuerzo suficiente. Los objetos dejados en los escombros incluyen varios documentos de papel, como anuncios impresos de la iglesia, textos históricos y religiosos, horarios de culto, partituras musicales escritas a mano, cartas, libros de cuentas y otros registros. Dado que estos materiales — que, razonablemente, pueden ser considerados valiosos, fueron dejados en el sitio-, creemos que los dominicos abandonaron el complejo de la iglesia poco después de la caída del muro. La arquitectura menor de quincha del pueblo aparentemente sufrió mucho menos daños que los altos muros de adobe; sin embargo, esta permaneció ocupada luego de que la orden religiosa dejara el área. 


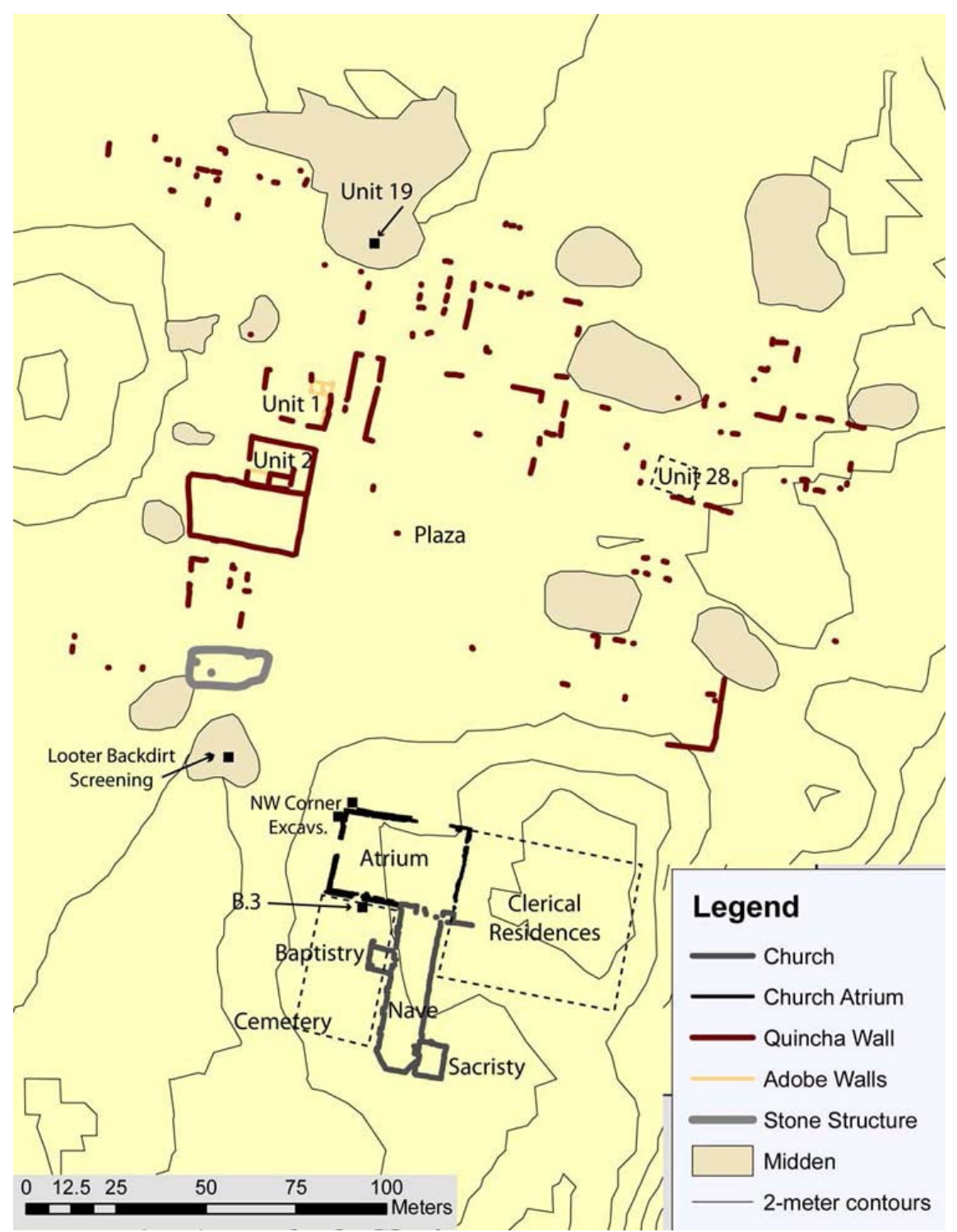

Figura 1. Plano de Magdalena de Cao Viejo a partir de las investigaciones arqueológicas. Se indica entre otros, la localización de la iglesia (church), el atrio (church atrium), muros de quincha (quincha wall) y adobe (adobe wall), una estructura de piedra (stone sttructure) y un basural (midden) (Plano por J. Quilter).

Además, encontramos fragmentos de papel sobre el piso de la ocupación doméstica del pueblo, que sugiere que el colapso de la iglesia ocurrió antes de que los «magdaleneros» cambiaran sus actividades económicas a ovejas y cabras (Fig. 4). La gente del pueblo parece haber minado la iglesia abandonada, lo cual es evidenciado por los extensos depósitos de tierra vieja, montículos ricos en artefactos en muchas áreas. La consistencia de estos depósitos sugiere que fueron hechos muchos años atrás, y no encontramos evidencia del siglo XIX o posterior. Partes del complejo de la iglesia fueron usados para procesar cuero, como lo indican las grandes cantidades de hojas y semillas de tara (también, conocidas como «taya» [Caesalpina spinosa]), utilizada para el curtido del cuero, así como un depósito de almacenamiento para el material asociado con un raspador de piel de madera cercano, construido en la pared oeste del atrio (Vásquez y Rosales 2008). 


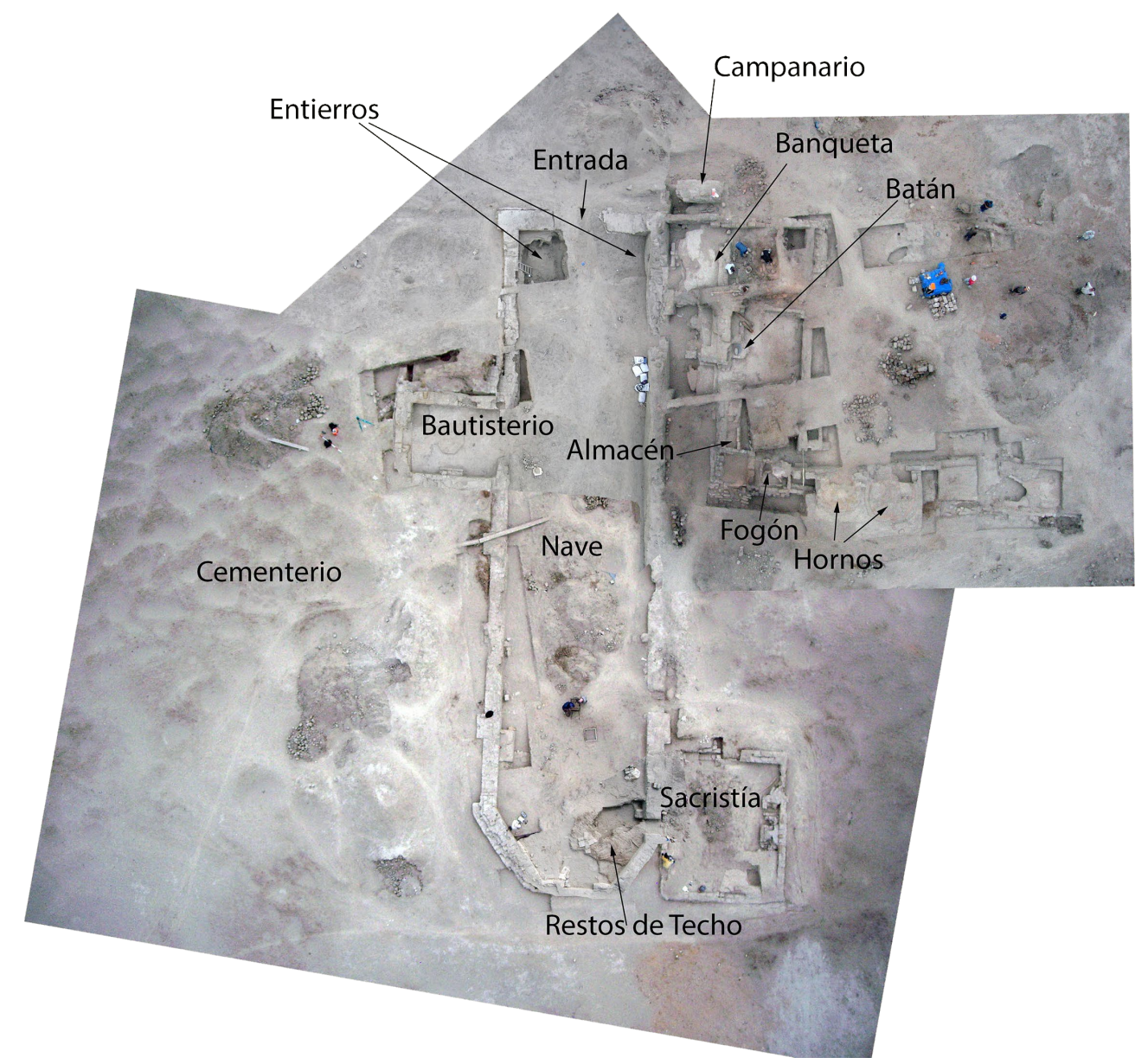

Figura 2. Foto aérea de los detalles arquitectónicos de la iglesia de Magdalena de Cao Viejo, revelados por las excavaciones arqueológicas (Foto por J. Quilter).

Alfonso Toribio de Mogrovejo, segundo arzobispo de Lima, provee la descripción más temprana de Magdalena en 1593, cuando visitó la comunidad (Benito 2006: 52). Él resalta que, en esa época, había 715 habitantes de los cuales 169 eran tributarios, cabezas masculinas de los hogares. En una visita en 1599, Pedro Martínez, un agente de Toribio, reportó 150 tributarios (Benito 2006: 166), por lo que podemos inferir que Magdalena fue una comunidad activa al menos hasta 1599. Los documentos de papel encontrados en las ruinas de la iglesia datan con seguridad de 1612 y posiblemente tan tarde como 1650. Tras esto, no estamos seguros de cuánto tiempo fue ocupado el pueblo. Magdalena fue nombrada en 1730, en un informe de un viaje marítimo por la costa norte del Perú y se sugiere que el pueblo era visible desde el océano (Ortiz Sotelo 1993; Castañeda 2006). A esto se le añade un mapa de 1763 de Miguel Feijoó de Sosa (1984 [1763]), que muestra a Magdalena en el litoral. En ese tiempo, Feijoó notó que 69 indígenas y 56 mestizos vivían en el sitio. Esta dramática disminución en el tamaño de la población puede indicar que, para este tiempo o poco después, el pueblo mayoritariamente criaba a sus animales y procesaba sus cueros.

En un mapa preparado por el arzobispo de Trujillo, Martínez Compañón, c. 1780, Magdalena se muestra tierra adentro, casi donde el pueblo moderno se ubica. Entonces, parece razonable inferir que Magdalena de Cao Viejo fue abandonada y el nuevo pueblo, aún ocupado hoy en día, se estableció en algún momento entre 1763 y 1780. Ninguna ocupación significativa se dio en 


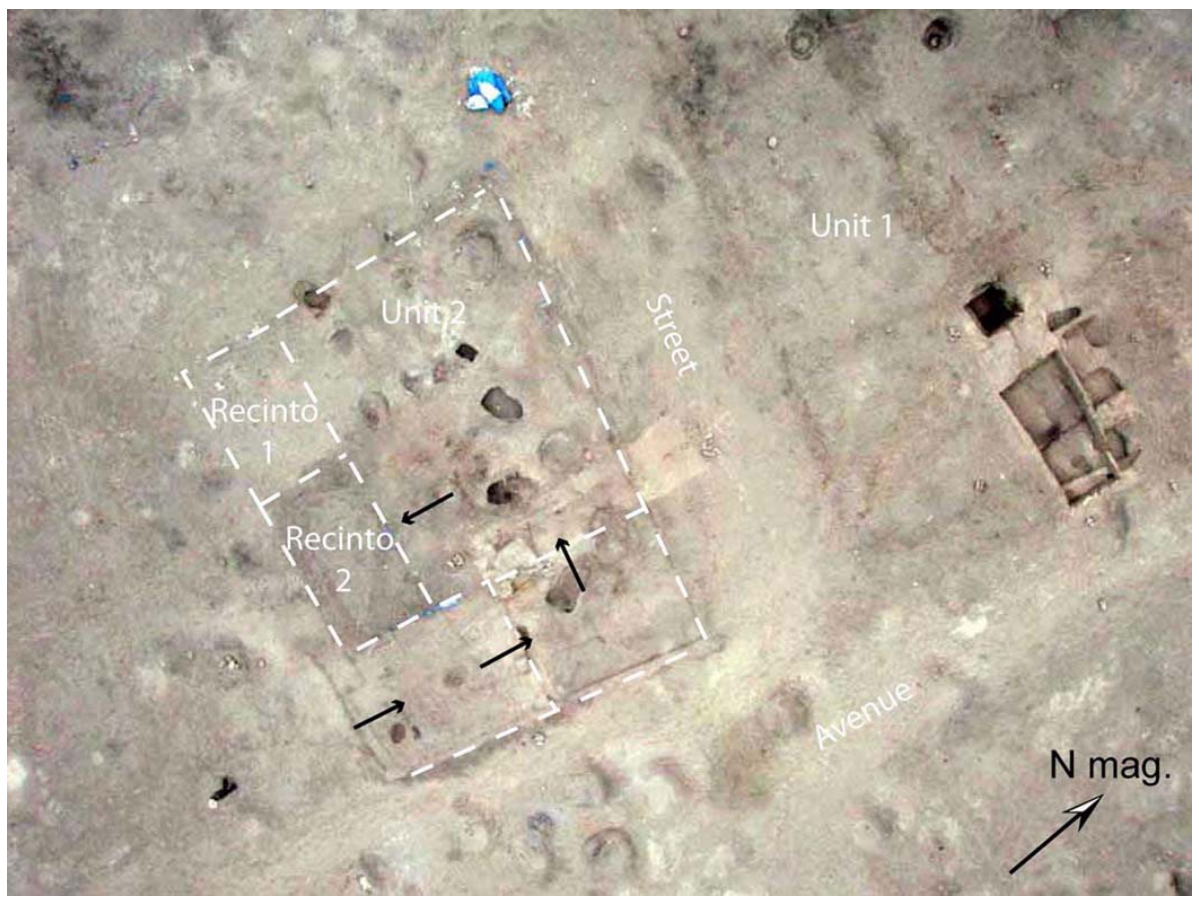

Figura 3. Foto aérea de las Unidades de Excavación 1 y 2: complejos residenciales de Magdalena de Cao Viejo (Foto porJ. Quilter).

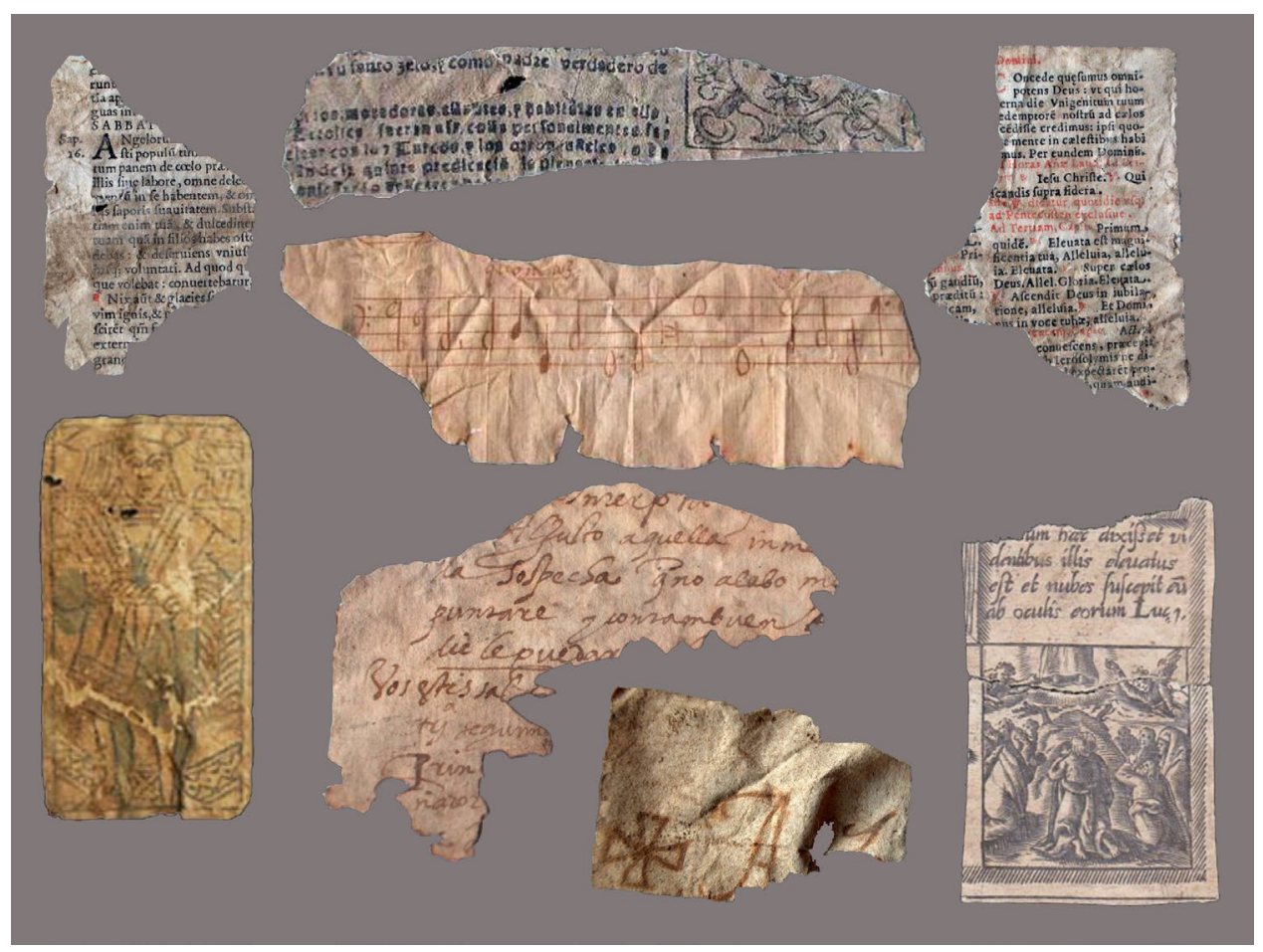

Figura 4. Ejemplos de fragmentos de papel encontrados en excavaciones en Magdalena de Cao Viejo (Foto por J. Quilter). 
El Brujo luego, salvo por el pequeño número de arqueólogos que ha trabajado regularmente desde 1990. Sin embargo, una pequeña comunidad de pescadores en la playa junto a Huaca Prieta ha habitado en el lugar desde tiempos precerámicos.

\section{Textiles y artesanías relacionadas}

Los textiles de Magdalena ofrecen una visión de las identidades sociales y las maneras en que el espacio fue restructurado bajo el régimen colonial (Brezine 2008). Hay muchos textiles fabricados con materiales europeos y estilos — como sábanas, encajes-, así como técnicas decorativas - como el bordado-, que fueron compartidos, pero que representan diferencias entre el Viejo y el Nuevo Mundo. Si bien los dos siglos de ocupación de Magdalena se constituyen como un período relativamente corto para los estándares prehistóricos, se dieron cambios significativos desde una perspectiva histórica. Aun así, estos cambios son difíciles de marcar arqueológicamente. Los cambios en las técnicas de tejido y los estilos de vestido son suficientemente bien conocidos, para Europa, por lo menos, como para separar textiles tempranos de los más tardíos, mientras que la ropa se constituye como una tarea difícil de definir, pues estos objetos fueron encontrados en la superficie del sitio, en depósitos de basura y en los restos que dejaron los saqueadores. También, debemos tener en cuenta que los cambios en los estilos pueden haber permanecido en la Colonia, en comparación con la patria europea, y que debe haber ocurrido un gran incentivo para llevar y utilizar prendas durante mucho más tiempo debido a su escasez.

En general, los análisis llevados a cabo sugieren que los hombres nativos adoptaron más rápidamente las formas de vestir en comparación con las mujeres, un patrón común en las sociedades colonizadas, en las que los hombres eran más activos en los quehaceres públicos con los extranjeros que las mujeres. Debemos tener presente, sin embargo, que solo pocas o tal vez ninguna mujer europea habitó en el sitio, así que probablemente hubo poca oportunidad para que las mujeres nativas aprecien estilos foráneos de vestir.

Hemos recuperado camisas, calzado, polainas, calzas o calcetines, y sombreros masculinos del estilo europeo. Las telas incluyen la seda y el lino, y los textiles fueron producidos mediante procesos distintos, como fieltro, damasco, adornos de encaje y los estilos de bordado europeos. Muchos de los artículos de vestir son fragmentos, lo cual hace difícil determinar si se trata de ropa masculina o femenina, pero muchos parecen ser artículos de vestir masculinos. Parece que las mujeres llevaron la ropa en un estilo tradicional, incluso, al envolverse en una tela cuadrada grande, o manto, sobre los hombros. Cualquier adaptación de la ropa femenina al estilo europeo falta ser documentada.

Aunque algunos hombres adoptaron artículos o aspectos del vestido europeo, las túnicas masculinas del estilo prehispánicos aún se llevaban. Hay dos variaciones de estas prendas: una que parece más tradicional, con rayas de azul y marrón, y un segundo estilo, que parece prehispánico. Este último consiste en un fondo marrón claro adornado con lunares pequeños de alpaca de color y un borde al pie del mismo material. Un asunto que aún queda por resolver es si que es un estilo nuevo indígena de la época colonial, una permanencia de un estilo prehispánico previamente no documentado o una modificación de un estilo preconquista.

Los artes textiles son un área en la cual es claramente visible la mezcla y sincretismo del sitio. Algunas telas de lana parecen ser teñidas después de ser tejidas, una práctica rara para los Andes, pero común en Europa, tal como el sobreteñido. Las tijeras y cizallas eran usadas y se conocían las costuras curvadas, lo cual sugiere que las ideas europeas de la tela entallada fueron adaptadas. Tanto botones de tela como cierres también han sido encontrados en las prendas del estilo europeo.

El estudio de los textiles Magdalena por Carrie Brezine (2008) claramente muestra prueba de la hibridez de las tecnologías de los estilos indígenas y europeos. Por lo menos, en el caso de los textiles, entonces, hay ejemplos claros de mezcla. En un textil, la urdimbre y la trama se hilan tradicionalmente en el algodón nativo, pero el diseño en sarga de la prenda imita el damasco europeo. Además, una anomalía en la tela sugiere que alguna técnica de automatización, quizás 

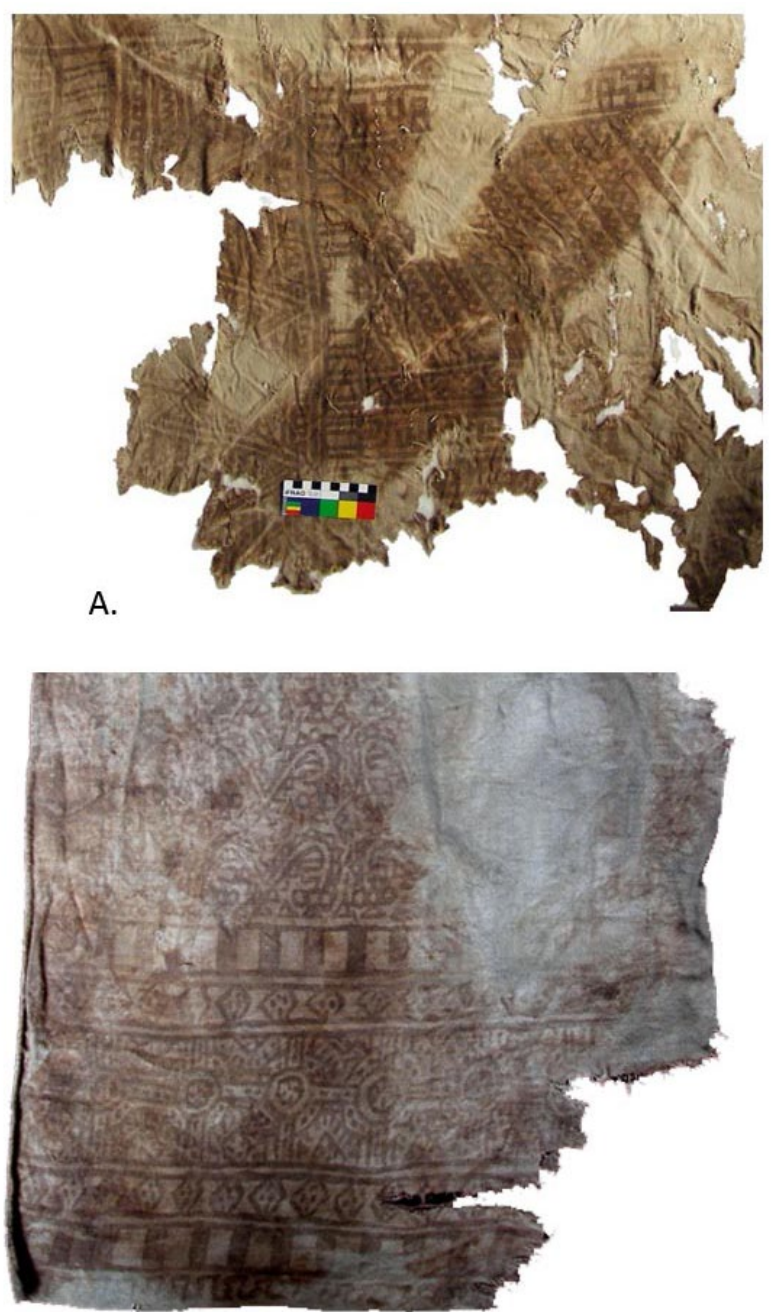

B.

Figura 5. Dos detalles de textiles pintados de Magdalena de Cao. A. Diseño en bloques. B. Diseño con cruces (Foto por J. Quilter).

un telar del estilo europeo, podía ser utilizado más que la tecnología tradicional andina, la cual dependió más en el manejo de los hilos por los dedos. Otro textil consiste en una tela impermeable hecha en la tradición indígena de las urdimbres de algodón en par y las tramas solas, pero expone un bordado en el estilo europeo. Otro ejemplo de la mezcla es el uso de las tijeras para confeccionar la ropa en parte o enteramente en la manera de los estilos europeos.

Se debe señalar que encontramos muchos ejemplos de fragmentos de los textiles pintados de marrón claro y oscuro (como aparecen ahora) en diseños geométricos en tela de algodón crema o blanca (Fig. 5). Aunque los textiles pintados son conocidos de tiempos tempranos en Perú —aún en uso, fueron populares en particular en la prehistoria tardía-, este estilo parece ser únicamente colonial. En el entierro más completo que encontramos, una mujer enterrada con dos bolsas pequeñas llenas de bolas de cordel textil llevó un manto de tela en este estilo.

Los diseños en los textiles que hemos limpiado y estudiado hasta ahora parecen ser diseños geométricos, sin precursores directos conocidos en las prehistóricas telas pintadas de la costa norte, pero tampoco forman parte de las convenciones artísticas europeas. Los textiles pintados parecen 
ser un tipo nuevo de prenda de tela adornada o, por lo menos, un estilo mucho más común que en las épocas previas. Cabe anotar que pintar es una manera económica y eficiente de adornar una superficie grande con rapidez. Si el adornar textiles de esta manera se acrecentó durante el período colonial, podría ser en parte por las circunstancias de estrés de la población nativa, la cual tuvo menos tiempo para tejer para los muertos que cuando era independiente. En términos generales, los textiles coloniales sugieren que la gente nativa adoptó con holgura muchos aspectos del vestido y tecnologías textiles europeos, a la par que mantuvo sus costumbres textiles propias como deseaban y, además, que los domínicos les permitieron hacer. Los textiles pintados pudieron haber sido desarrollados bajo condiciones de explotación, pero no hay pruebas concluyentes de resistencia en ellos.

Muchos de los tejidos en el estilo más tradicional demuestran imágenes aparentemente inocuas de pájaros y peces estilizados, que no parecen soportar una carga llena de símbolos. Si una resistencia estaba siendo expresada en estos diseńos, no la podemos ver y, por supuesto, puede ser que fueron usados para que los frailes españoles tampoco pudieran verla. No obstante, muchos de estos diseños parecen haber sido comunes y relativamente sin simbolismo en los tiempos precontacto también. Un obstáculo serio al entendimiento de los patrones de resistencia, tanto con cambios directos como sencillos, es nuestra falta relativa de conocimiento detallado de la cultura material y los sistemas simbólicos inmediatamente previos a la conquista entre la gente común.

\section{La práctica y cultura material religiosa}

Excavamos áreas substanciales de habitaciones para vivienda en dos complejos domésticos, Casa 1 y 2, durante nuestra investigación y colocamos excavaciones grandes de prueba en una tercera, Casa 28 (Van Valkerburgh 2007). Este trabajo incluyó la excavación completa de un área de cuatro por seis metros (Recinto 2) en la Casa 2 y un área del mismo tamaño en la Casa 1 . En ambos casos, los pisos de las ocupaciones tempranas contuvieron varios ejemplos de ofrendas. Estas consistieron comúnmente en mates cortados o cuencos de mate que llenaron con capas múltiples de tela envuelta y doblada conteniendo semillas, vainas, hojas y artículos comestibles similares, la mayoría restos vegetales. Muchos de los textiles en estos atados con frecuencia fueron desgarrados y hechos jirones.

En la Casa 1, encontramos dos ejemplos de la iconografía cristiana: una cruz pequeña de madera (3,6 centímetros de altura) y un crucifijo de metal (2,6 centímetros de ancho). Ambos se encontraron en la Casa 1, donde ofrendas del estilo tradicional fueron colocadas en los pisos. Aunque los artículos cristianos parecen haber sido depositados durante una época un poco más tardía que la mayoría de las ofrendas, creemos que por lo menos algunos de los depósitos subterráneos pudieron haber sido contemporáneos con la vida de uso de la cruz y el crucifijo. Mientras los mates llenos se depositaron deliberadamente, los artefactos cristianos parecen haber sido desechados. Efectivamente, muchos objetos - como un par de anillos incrustados en la Casa 28, los cuales pudimos suponer que fueron guardado cuidadosamente- se encuentran en los suelos de las casas en Magdalena, lo cual plantea preguntas sobre el tipo de valor puesto en ellos. Quizás, este es un indicador de la actitud de los nativos hacia los bienes foráneos, como interesantes pero prescindibles.

Un ritual que involucra materiales que arden lentamente en cuencos de mate fue realizado en el sitio, aunque esta posiblemente no fue una práctica que ocurrió directamente dentro de una casa (Fig. 6). Encontramos dos ejemplos concluyentes de esto y, en una ocasión, una cuenta «veneciana" grande de colores blanco y azul con rojo fue encontrada en medio del material quemado. La excavación en la cual se hallaron estas ofrendas era una unidad de uno por dos metros, así que fue difícil determinar el contexto de los depósitos. Podía ser un basural, aunque algunas capas indiquen que residencias estaban ubicadas en el área durante la época colonial. Sea un basural o barrio, la ubicación fue en el fondo del pueblo, tan lejos de la iglesia como fue posible, y pudo haber sido realizada clandestinamente. 

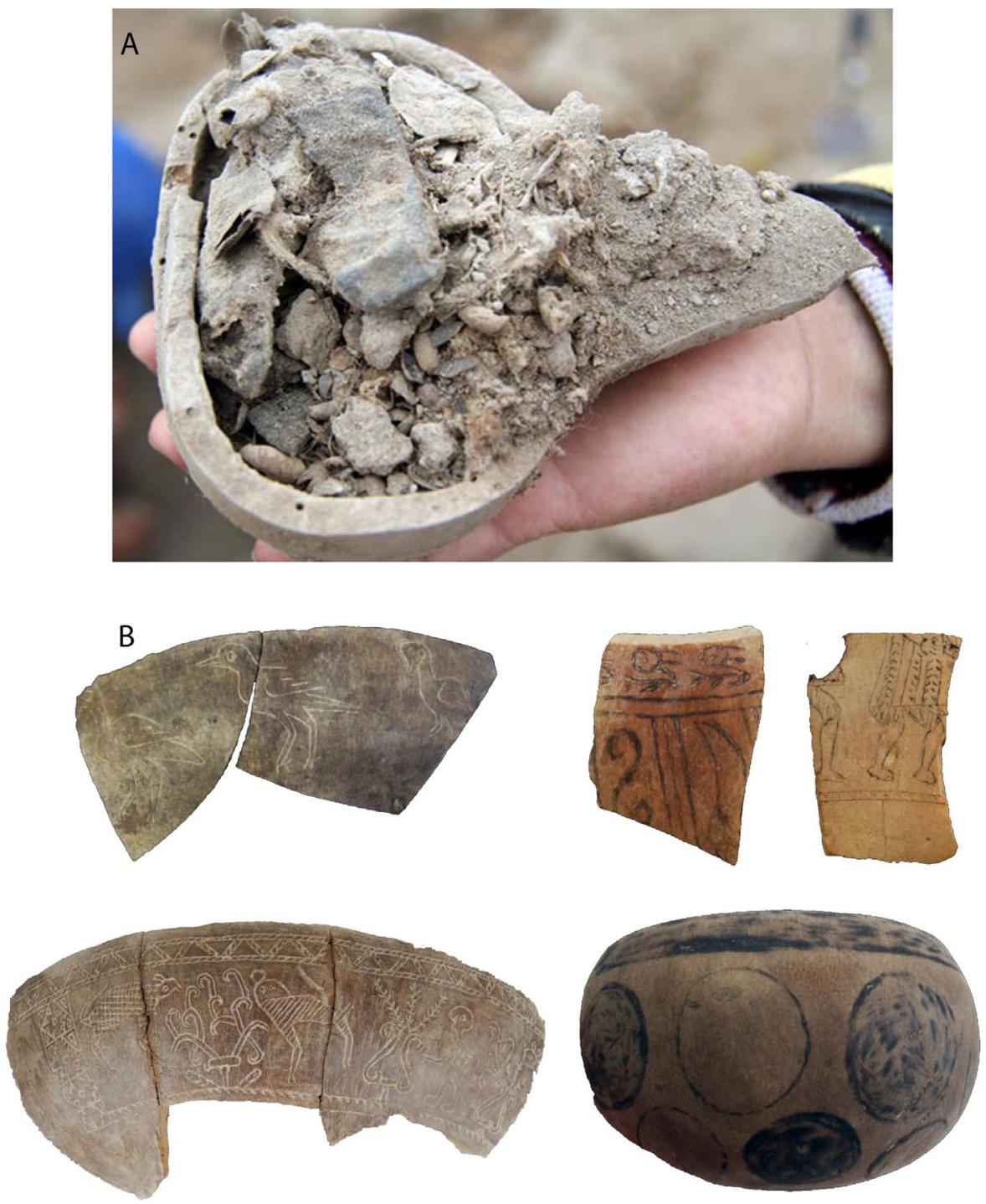

Figura 6. A: Una ofrenda en un maté cortado, proveniente de un piso bajo en la Casa 1 (Unidad 1). B: Mates $y$ fragmentos de mates decorados hallados en Magdalena de Cao (Foto por J. Quilter).

Conchas Spondylus también se encontraron en el estrato en esta excavación y también fueron frecuentes en las casas. Como uno de los componentes esenciales de las rituales en los Andes, su presencia parece proponer que las creencias y los ritos tradicionales continuaron. Sin embargo, esta evidencia está abierta a múltiples interpretaciones.

La casa prehispánica y las prácticas rituales similares en el pueblo pueden ser comparadas con la evidencia en la iglesia, que, por lo menos, ofrece más de una interpretación simple y directamente cristiana. Una concha de Spondylus fue encontrada colocada en el suelo de un cuarto al lado del santuario de la nave de la iglesia, lo que hemos interpretado como la sacristía; la oficina del cura; y, en este caso, posiblemente su residencia. La concha se colocó en una capa delgada de tierra justo sobre el piso de revoque. Esto sugiere que la concha fue colocada en la sacristía después del fin del uso del cuarto; así podría ser interpretada como una forma de resistencia. 
¿O fue una manera simple de santificar el sitio de nuevo o solo un reconocimiento de su importancia sagrada?

Menos ambivalente en términos de las acciones involucradas, pero quizás más desconcertante respecto al intento en comparación con el Spondylus en la sacristía, fue el descubrimiento de la parte inferior de una pierna y el pie de un individuo colocado en la pared de la sacristía. La tibia y el peroné conectados al pie habían sido insertados o puestos ahí al momento de haber construido el muro, aunque la presencia de algún tipo de distorsión de los ligamentos era evidente, lo que causa que la planta no sea completamente llana. Los restos humanos fueron colocados justo detrás de un caballón de adobes grande, construido contra el interior de la pared, posiblemente como un altar personal para el cura. De este modo, el extremo proximal de los huesos de la pierna no habría sido visible desde el interior del cuarto y, con revoque suficiente, el pie no habría sido visible al exterior de la sacristía.

¿Qué podemos interpretar de este pie y pierna en la pared detrás del altar? ¿Es una práctica andina, cristiana o híbrida? ¿Supieron los curas de esta práctica o fue realizada en secreto? Los vectores sociales que condujeron a la colocación de los restos parciales de un ser humano en esta pared — la dominación, resistencia, sincretismo o mezcla — son muy inciertos. Aún, la inserción de esta pierna dentro de la pared, posiblemente justo detrás del altar personal del cura, quizás es la sugerencia más fuerte de la expresión de la resistencia o, quizás con más precisión, la subversión y desafío en el sitio.

\section{Papel}

La diferencia entre prehistoria e historia, entre sociedades letradas e iletradas, comúnmente ha sido vista como una profunda división, fundamentalmente, entre diferentes modos de vida. Los documentos españoles sirvieron para definir, reprimir y subyugar al pueblo nativo. No obstante, los pueblos andinos aprendieron rápidamente a usar el sistema que los reprimió (los procedimientos jurídicos, en particular) para luchar y para recuperar muchas de sus pérdidas (Stern 1982: 37-114). La introducción de documentos y la acción social llevó a lo que fue tal vez el más profundo cambio en las vidas de los nativos andinos en la transición de la prehistoria a la era colonial. Dado todo esto, podríamos esperar actitudes innatas hacia los documentos, un área en que la resistencia o alguna otra profunda estancia social o acción deberían ser claramente evidentes; sin embargo, reina la ambigüedad.

Cuando los muros de la iglesia de Magdalena de Cao colapsaron, ellos atraparon un gran número y variedad de documentos. Si los frailes recuperaron algunos libros o archivos, también, dejaron muchos otros, incluidos los que parecen ser tomos muy valiosos, tales como himnarios, escritos en hojas doradas a tinta, y otros volúmenes decorados a mano que habrían sido espiritual y monetariamente valiosos. Los manuscritos que hemos encontrado ofrecen una visión única de la vida de la comunidad monástica, y no solo incluyen himnarios y partituras de música, sino también libros de cuentas, cartas personales, notas y garabatos en documentos escritos a mano, así como páginas impresas para breviarios, leccionarios, historias de la iglesia y profanas, calendarios de días de los santos y similares. La profesora Karen Spalding ha trabajado en la identificación del extenso rango de los materiales que hemos encontrado.

Con la totalidad de la iglesia abandonada, la gente del pueblo extrajo papel —así como otros materiales de las ruinas - y lo usaron de varias formas. En el pueblo, encontramos muchas tiras pequeñas de papel para los que no podemos determinar un uso específico. Estos fragmentos de papeles son a menudo relativamente pequeños: aproximadamente, no miden más que dos centímetros por tres o cuatro centímetros sobre un lado, mientras otros son tiras largas y delgadas. Incluso aquí no hay un patrón consistente; pese a ello, algunos papeles pueden ser largos o pequeños. Por otro lado, una característica común es que el papel es cortado en pequeñas partes y hay pocos ejemplos de páginas enteras de documentos en el pueblo (Fig. 7). En el área de la iglesia, a menudo, hemos encontrado piezas largas de papel, y, en un par de casos, varias hojas de papel 


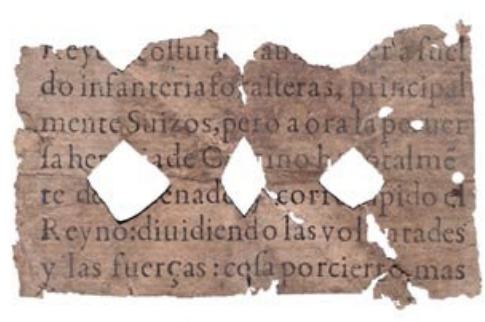

A.

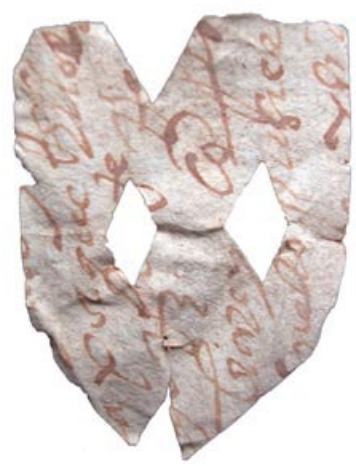

C.

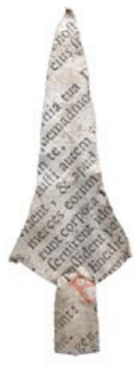

D.

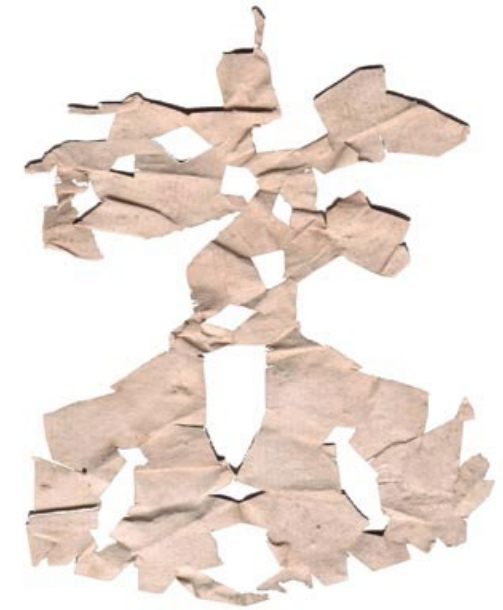

B.

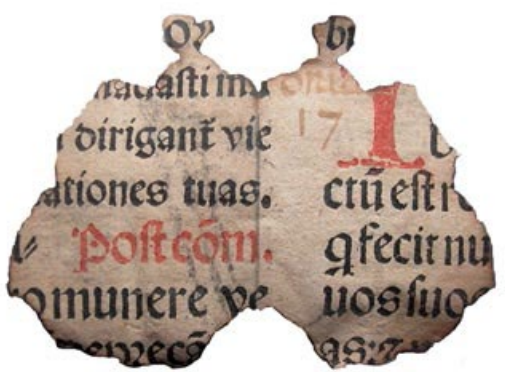

E.

Figura 7. Papeles cortados de Magdalena de Cao Viejo. Tamaños relativos y sin escala. Anchos máximos indicados. A. Diamentes (7.c cm); B. Geométricos (7.25 cm); Masquera (4 cm); Punta de lanzón (5.2 cm); E. Mariposa (5.1 cm) (Foto por J. Quilter).

encuadernados en un libro o libro de contabilidad. Aparentemente, las largas hojas fueron adquiridas en el área de la iglesia y, luego, fueron cortadas en pequeños fragmentos en sitios domésticos del pueblo. Las pequeñas piezas de papel en el ámbito doméstico no muestran un claro patrón de ubicación que seamos capaces de detectar.

Un frecuente uso del papel fue la introducción de recortes hechos desgarrando el papel con las manos, o, aparentemente, a través del uso de tijeras o alguna otra herramienta afilada (Fig. 7). Algunos papeles cortados son deliberadamente trabajados, pero carecen de un claro contenido iconográfico con formas geométricas. Hay únicamente tres formas reconocibles: una cara o máscara estilizada, una hoja de lanza y una mariposa (Fig. 7 C-E). ¿Qué podemos hacer con ellos? Podemos interpretarlos de muchas formas: desde un profundo compromiso con los instrumentos de opresión (hoja de lanza), vuelos literales de fantasía (mariposa), o una cara o mascara abstracta que puede ser interpretada de variadas y numerosas formas.

Podemos considerar que, si estos restos hubieran sido hechos de tela y en la era prehistórica, o si hubieran sido encontrados en un contexto histórico indudablemente europeo, sus significados podrían haber sido todavía más difíciles de interpretar. El hecho de que se encuentren dispersos en un basural sugiere que no tenía ningún aura sagrada y se desecharon fácilmente una vez que su uso terminó. 


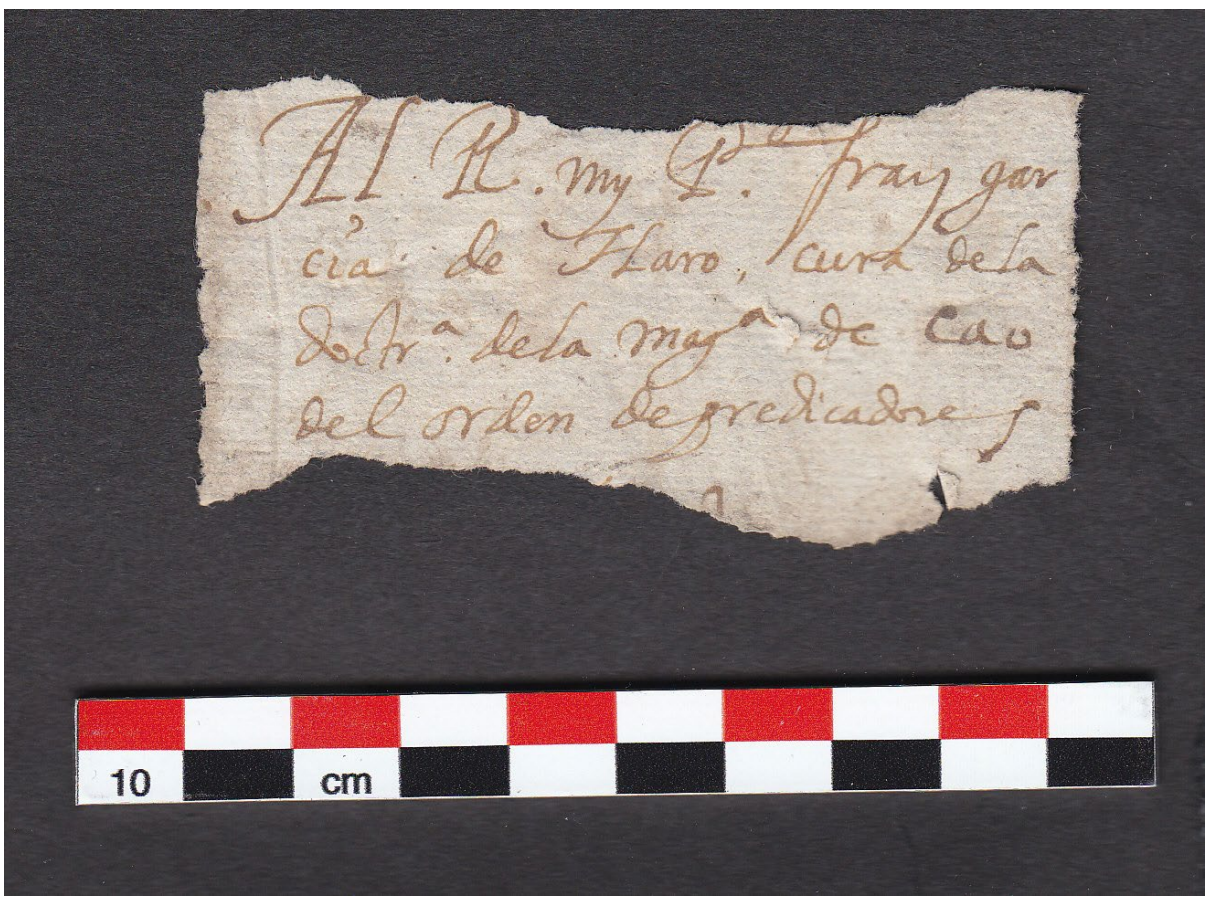

Figura 8. Fragmento de una carta dirigida al cura Garcia de Haro (Foto por J. Quilter).

Finalmente, menciono dos extraordinarias piezas de papel. Una es un fragmento al que alude el sacerdote del sitio: García de Haro y el nombre «Mag. De Cao» (Fig. 8). No muchos arqueólogos tienen la suficiente suerte de estudiar a las personas que dejaron una nota con el nombre en el sitio. La segunda pieza es una carta completa sobre un asunto mundano. No obstante, sobre la parte posterior hay una lista de números con sus equivalencias en un lenguaje previo desconocido. Un artículo ha sido publicado sobre esto, pero el tema merece mucho más estudio (Quilter et al. 2010).

\section{Pensamientos finales}

La materialidad de los procesos sociales en la conquista y períodos coloniales tempranos del Nuevo Mundo no es fácil de identificar (Liebmann 2008a; Liebmann y Murphy 2008). Incluso, la abierta resistencia puede dejar pocos rastros, como las huellas de poderosas batallas que se pueden desvanecer sobre el terreno en un tiempo dado y la debilidad de la memoria, sin mencionar la eliminación de los materiales y los cuerpos de los entierros. A pesar del rico registro material de la ocupación colonial de Magdalena de Cao, que nos ofrece la posibilidad real de buscar las actitudes de adaptación, resistencia y la ambivalencia del sojuzgador y sojuzgado, identificar comportamientos asociados con tales actitudes (que pueden haberse desplazado en las mentes de las personas que vivieron en aquellos tiempos, y a que, con el paso del tiempo, se volvieron difíciles de desentrañar para la arqueología) resulta muy difícil.

El registro arqueológico en Magdalena de Cao Viejo manifiesta la continuidad de la cultura material precontacto; la adopción de objetos y prácticas europeas; y la mezcla de las dos en mayor o menor medida, dependiendo del material en cuestión. Cómo estas cosas fueron usadas, y qué se pensó de ellas, o cómo varias estrategias sociales fueron empleadas son aspectos muy difíciles de determinar, aunque tenemos muchos indicios de esto. Hay otros aspectos de la temprana vida colonial, tales como la adopción de plantas y animales europeos domesticados, o la diversa 
continuidad y cambios en el uso de las vasijas de cerámica, que no son discutidos aquí. El examen de estos y otros aspectos puede ayudar a desarrollar una visión más completa de temas de resistencia, y otros comportamientos y actitudes.

Sin embargo, un aspecto fundamental al trabajar estos temas es desarrollar un mejor entendimiento de la vida en el norte del Perú, antes del arribo de los españoles — tal como está disponible en el valle del Colca al sur del Perú (Wernke 2008)—, de modo que podamos documentar cambios y continuidades. Actualmente, la vida diaria en el Período Prehispánico Tardío del norte del Perú, especialmente para la gente común, es pobremente conocida. Por ejemplo, hemos visto evidencia de cerámica de estilos indígenas junto con cerámicas vidriadas; no obstante, nos enfrentamos a una tarea más difícil en distinguir los estilos de la cerámica nativa en términos de vincular la prehistoria tardía con las finas cerámicas de estilo europeo. Muchos más años de estudios tenemos por delante para poder hacer finos análisis de producción y distribución de ambos estilos cerámicos, indígenas y europeos, así como están disponibles para otras áreas del Período Colonial Temprano del Nuevo Mundo (Charlton y Fournier 2008).

Tal apreciación sobre la variabilidad en relaciones nativo-español es muy diferente de las visiones de George Kubler (1961: 32; cf. Quilter 1996) acerca de un «total remplazo de asuntos simbólicos» de civilizaciones indígenas americanas por los españoles. En efecto, para muchos estudiosos, nos hemos movido más allá del sincretismo - e, incluso, la mezcla — para ver el encuentro nativo-espańol como un evento marcadamente señalado; sin embargo, uno fue un momento en un proceso de continuidad cultural de cambios, que incluyeron préstamos, absorción y mezclas, así como acciones y dominación, resistencia, adopción y ambivalencia, y otros, como actitudes o planteamientos culturales a veces públicos, a veces convertidos, a veces conscientes y a veces en parte de ellos. El lenguaje y la cultura pueden ser entendidos como parte de un solo universo en constante proceso dialógico (Tedlock y Mannheim 1995); así fue la experiencia de españoles y nativos.

Hace pensar que, de muchas formas, los mundos físicos y universos morales de españoles y nativos en el Perú tardío del siglo XVI fueron mucho más parecidos que cualquiera de sus contemporáneos euroamericanos. Ellos vivieron en un «mundo iluminado por el fuego», mientras nosotros fijamos la vista en el brillo de las computadoras y televisores, y la visión que ellos tuvieron y que tenemos en esas varias luces son aspectos muy diferentes. Períodos más cortos de tiempo pueden, no obstante, todavía ser significativos. Muchas de las personas quienes establecieron el pueblo sobre el terreno de El Brujo eran cercanos a Atahualpa, muchos de sus parientes podrían ser reconocidos, pero únicamente muy pocas de las personas antiguas podrían recordar la vida antes del arribo de los españoles, y la mayoría tendría únicamente conocimiento de aquellos tiempos a través de los ojos de su infancia.

Estos desvanecimientos de memoria se constituyen como una de las razones para que la década de 1570 pueda ser vista como la transición de la era de la conquista al período colonial. La otra razón, muy relacionada con la primera, es el virreinato de Francisco Toledo. Para bien o mal, él estableció órdenes en un mundo que fue caótico para más de dos generaciones (Zimmerman 1938). Los académicos tienden a defender a los nativos. Biografías personales, experiencias de campo y - tal vez- el sentido de marginación de los estudiosos para una sociedad cada vez menos intelectual, combinados con la maravilla de lo que el mundo puede ser si «El encuentro» nunca hubiera ocurrido o se hubiera retrasado, nos hace defender a los incas antes que a los españoles. Sin embargo, tenemos que tomar el mundo por lo que es y no por lo que quisiéramos que fuera. Así lo hizo la población de Magdalena de Cao. La forma como sobrellevaron la realidad es lo que estamos estudiando en nuestras presentes investigaciones en el sitio.

\section{Nota y agradecimiento}

Este capítulo es una revisión y traducción de un capítulo publicado, originalmente, como «Cultural Encounters at Magdalena de Cao Viejo in the Early Colonial Period» en Enduring Conquests: Rethinking the Archaeology of Resistance to Spanish Colonialism in the Americas, editado 
por Matthew Liebmann y Melissa S. Murphy, de la editorial del School for Advanced Research, Santa Fe, NM.

Quisiera agradecer a los organizadores del Primer Simposio Internacional de Arqueología Histórica en el Perú: Rosabella Âlvarez-Calderón, Zach Chase, Abel Traslaviña, Nathaniel P. Van Valkenburgh, y Brendan Weaver, así como a mis colegas de la Pontificia Universidad Católica del Perú, especialmente, a los profesores Marco Curatola-Petrocchi y Luis Jaime Castillo. Agradezco también al señor Marco Aveggio de la Fundación Wiese, Régulo Franco Jordán, Carmen Gamarra, María Fernanda Boza, Carrie Brezine, Tom Cummins, William Doonan, R. Jeffrey Frost, Catherine Gaither, Danielle Olga Mirabal, Melissa Murphy, Michele Koons, O. Gabriel Prieto, Hal Starratt, Jennie O. Sturm y Lisa Trever.

\section{REFERENCIAS}

Benito, J. A.

2006 Libro de visitas de Santo Toribio Mogrovejo (1593-1605), Fondo Editorial de la Pontificia Universidad Católica del Perú, Lima.

Brezine, C.

2008 Preliminary report on the textiles from the colonial site of El Brujo, Summer 2008, documento en el archivo del Peabody Museum of Archaeology and Ethnology, Harvard University, Cambridge.

Castañeda, J.

2006 Etnohistoria de Magdalena de Cao, Informe de Investigación, documento en el archivo del Peabody Museum of Archaeology and Ethnology, Harvard University, Cambridge.

2007 Eventos de historia ambiental en el valle de Chicama, siglos XVI-XIX, documento en el archivo del Peabody Museum of Archaeology and Ethnology, Harvard University, Cambridge, MA.

Charlton, T, H. y P. Fournier

2008 Pots and plots: The multiple roles of early colonial red wares in the asin of Mexico (identity, resistance, negotiation, accommodation, aesthetic creativity, or just plain economics?), en: M. Liebmann y M. S. Murphy (eds.), Enduring conquests: Rethinking the archaeology of resistance to Spanish colonialism in the Americas, 127-148, School for Advanced Research Press, Santa Fe.

Feijoó de Sosa, M.

1984 Relación descriptiva de la ciudad y provincia de Truxillo del Perú, edición facsimilar, Banco Industrial del [1763] Perú, Lima.

Kubler, G.

1961 On the colonial extinction of the motifs of pre-Columbian art, en: S. K. Lothrop, (ed.), Essays in preColumbian art and archaeology, 14-34, Harvard University Press, Cambridge. https://doi.org/10.4159/ harvard.9780674864917.c4

Liebmann, M.

2008 The best of times, the worst of times: Pueblo resistance and accomodation during the Spanish reconquista of New Mexico, en: M. Liebmann y M. S. Murphy (eds.), Enduring conquests: Rethinking the archaeology of resistance to Spanish colonialism in the Americas, 199-222, School for Advanced Research Press, Santa Fe, NM.

Liebmann, M. y M. S. Murphy (eds.)

2008 Enduring conquests: Rethinking the archaeology of resistance to Spanish colonialism in the Americas, School for Advanced Research Press, Santa Fe, NM.

Ortiz, Sotelo, J. (ed.)

1993 Derrotero general del mar del sur del capitán Pedro Hurtado de Mendoza, hecho por capitán Manuel Joseph Hurtado en el Puerto del Callao - año de 1730, Dirección de Intereses Marítimos, Lima.

Quilter, J.

1996 Continuity and disjunction in pre-Columbian art and culture, RES: Anthropology and Aesthetics 29/30, 303-317. https://doi.org/10.1086/RESvn1ms20166956 
Quilter, J., M. Zender, K. Spalding, R. Franco, C. Gálvez. y J. Castañeda

2010 Traces of a lost language and number system discovered on the North Coast of Peru, American Anthropologist 112 (3), 357-369. https://doi.org/10.1111/j.1548-1433.2010.01245.x

Stern, S. J.

1982 Peru's Indian peoples and the challenge of Spanish conquest: Huamanga to 1640, University of Wisconsin Press, Madison.

Tedlock, D. y B. Mannheim

1995 The dialogic emergence of a culture, University of Illinois Press, Champaign.

Van Valkenburgh, N.

2007 Informe de excavaciones en la Unidad 2, Sector-Pueblo, sitio-Colonial, Complejo Arqueológico El Brujo, julio-agosto 2007, informe en el archivo del Peabody Museum of Archaeology and Ethnology, Harvard University, Cambridge.

Vásquez, V. y T. Rosales

2008 Análisis de restos de fauna y vegetales de la iglesia y pueblo-complejo arqueológico El Brujo, informe en el archivo del Peabody Museum of Archaeology and Ethnology, Harvard University, Cambridge.

Wernke, S. A.

2008 Convergences: Producing early colonial hybridity at a doctrina in highland Peru, en: M. Liebmann y M. S. Murphy (eds.), Enduring conquests: Rethinking the archaeology of resistance to Spanish colonialism in the Americas, 77-102, School for Advanced Research Press, Santa Fe.

Zimmerman, A. F.

1938 Francisco de Toledo: Fifth viceroy of Peru, 1569-1581, The Caxton Printers, Caldwell. 